\title{
Dynamic Demand and Pricing Inventory Model for Non- Instantaneous Deteriorating Items
}

\author{
Nita H. Shah \\ Department of Mathematics, Gujarat University, \\ Ahmedabad-380009, Gujarat, India. \\ Corresponding author: nitahshah@gmail.com \\ Kavita Rabari \\ Department of Mathematics, Gujarat University, \\ Ahmedabad-380009, Gujarat, India. \\ E-mail: kavitagalchar1994@gmail.com \\ Ekta Patel \\ Department of Mathematics, Gujarat University, \\ Ahmedabad-380009, Gujarat, India. \\ E-mail: ektapatel1109@gmail.com
}

(Received April 21, 2020; Accepted September 12, 2020)

\begin{abstract}
In this model, an inventory model for deteriorating products with dynamic demand is developed under time-dependent selling price. The selling price is supposed to be a time-dependent function of initial price of the products and the permissible discount rate at the time of deterioration. The object is sold with the constant rate in the absence of deterioration and is the exponential function of discount rate at the time; deterioration takes place. Here, the demand not only dependent on the selling price but also on the cumulative demand that represents the saturation and diffusion effect. First, an inventory model is formulated to characterize the profit function. The Classical optimization algorithm is used to solve the optimization problem. The objective is to maximize the total profit of the retailers with respect to the initial selling price and cycle time. Concavity of the objective function is discussed through graphs. At last, a sensitivity analysis is performed by changing inventory parameters and their impact on the decision variables i.e. (initial price, cycle time) together with the profit function.
\end{abstract}

Keywords- Dynamic demand rate, Deterioration rate, Time-dependent selling price, Variable holding cost, Discount.

\section{Introduction}

Initially, retailers would have belief that goods have infinite life time, while the hypothesis is not true in real world. Due to the scientific reasons, the implication of deterioration has been tinted. Products such as electronics goods, gasoline, blood, grains start getting deteriorate after a particular time period and losses its originality. Therefore, deterioration plays a vital role in inventory management and is the issue of major concern. Company may reduce the loss, by generating different marketing strategy and promotional tools like discount policy. Consumer's demand is dependent on products life time as well as on the selling price. In classical inventory models, demand rate is considered to be constant, independent of selling price, time and stockavailability that is not true in actual. Demand rate is highly affected by the selling price. Selling price is the key factor that directly influences the optimum solution. For examples, customers prefer to shop during sale. Hence, applying proper pricing policy facilitates the companies in handling the inventory system. Not surprisingly, hotels, airlines are using dynamic pricing 
International Journal of Mathematical, Engineering and Management Sciences

Vol. 6, No. 2, 510-521, 2021

https://doi.org/10.33889/IJMEMS.2021.6.2.031

strategies related to the demand and rate of deterioration and will offer certain opportunities for profitability. Here, in this model an inventory model for perishable objects with time-dependent selling price is introduced with permissible discount rate for the products that are getting damage with time. Additionally, the model considers variable holding cost as it increases with time, for taking care of perishable objects to prevent the spoilage and maintain the freshness. The demand rate for the objects depends not only on the selling price of the products but also on the cumulative demand or sale. Because of the dynamics of supermarkets and product characteristics, companies are facing problems. In fields like electronic products and fashion designing, a demand for the product decreases with time. Initially, people got attracted towards the new product, as human mind is always anxious to know something new but with time it slows down and losses its demand. By considering demand as a function of dynamic pricing is a powerful strategy. Dynamic pricing will help to change the demand according to the desire and need. Company have to face many challenges with constant selling price when dealing with perishable products. These problems inspire the study. Instead of taking constant selling price, dynamic pricing policy is more effective to maximize the revenue rate. Also, to recover loss due to deterioration, the model introduces discount policy with variable holding cost. The model is formulated for dynamic demand with dynamic pricing under permissible discount for perishable products.

The rest of the article is structured as follows: Section 2 includes literature review. Section 3 represents the notation and assumptions that are used throughout the paper. Section 4 represents an inventory model to maximize the total profit. Computational algorithm to find feasible solution is carried out in Section 5. Section 6 describes numerical examples followed by managerial implications. Section 7 concludes the article with future scope.

\section{Literature Review}

The study is mainly related to dynamic demand with dynamic pricing for perishable objects. Avinadav et al. (2017) analysed an EOQ model for perishable objects where demand rate is a function of selling price, product's expiration date and promotion expenditure. Moreover, the independence of selling price on promotion expenditure is shown. Bakker et al. (2012) presented an up-to-date review of inventory model for perishable objects. Contribution to the inventory models are highlighted through terms like lost sale, discount policy and backordering. Feng et al. (2013) presented an optimal control model to minimize total cost function by considering production cost, remanufacturing cost, disposal cost and loss generated due to damages. Additionally, it is proved that the dynamic optimal policy is much better than static optimal policy. Feng et al. (2018) proposed a model for perishable objects where the demand is sensitive to time and price. The characteristic of production policy and joint dynamic pricing is discussed by solving optimal problems through Pontryagin's maximum principle. Shah et al. (2013) studied the marketing policy for non- instantaneous perishable products where the demand rate is dependent on selling price and advertisement of an item. An algorithm is formulated to maximize the total profit. Shah and Vaghela (2017) developed an EOQ model for perishable products under the effect of inflation. The demand rate is advertisement and time- dependent. Dynamic pricing practices are highly useful to increase demand and recover the loss that causes due to deterioration. Transchel and Minner (2009) analysed the effect of dynamic pricing on retailer's decision. The objective is to maximize total profit by considering an optimal order quantity and pricing policy where the retailer is permitted to change the price with time. Gupta et al. (2006) proposed a discrete-time model for arranging clearance price. Also, an algorithm is formulated for calculating near-optimal prices and tests its accuracy by numerical experiments. Xue et al. 
International Journal of Mathematical, Engineering and Management Sciences

Vol. 6, No. 2, 510-521, 2021

https://doi.org/10.33889/IJMEMS.2021.6.2.031

(2016) developed a dynamic pricing problem for perishable products with respect to reference price. The model is formulated to maximize total profit in which the demand is dependent on both on current and historical price. Dasu and Tong (2010) introduced an inventory model for perishable products under dynamic pricing policies. Cai et al. (2013) studies a dynamic pricing where the selling price is a function of time and holding cost is a quadratic function of inventory level. Rabbani et al. (2015) proposed a model for non-instantaneous perishable products for timedependent selling price. Xue and Zhu (2019) developed a model for deteriorating objects. Partially myopic and forward -looking behaviour for dynamic pricing is being analysed. The dynamic demand is not only dependent on the selling price but also on the cumulative sale of the products. An optimization problem is solved through pontryagin's maximum principle. Pang (2011) studies an inventory model for dynamic pricing and inventory policies under fixed additive demand and ordering cost. Bitran and Caldentey (2003) introduced an overview of pricing models and examine the effect of dynamic pricing on profits. Qin et al. (2014) developed a model for quality and physical quantity deterioration in which the demand is depending on the stock-level and the selling price. Wee and Law (2001) introduced a pricing policy for perishable products under time-value of money. An inventory model for perishable products under reference price effect when demand is stock and price sensitive (Hsieh and Dye, 2017). The work is new as first time a dynamic demand is considered that is effected both by the selling price and cumulative demand where the selling price is taken as a time-dependent function with permissible discount rate for the time interval when deterioration takes place to boost the sale. Feng et al. (2020) developed an inventory-based pricing model under lost sale. Golrezaei et al. (2020) introduced a model showing, dynamic pricing is more effective strategy for maximizing total profit for heterogeneous time-sensitive customers. Also, modify the effect of holding cost and production rate on the management. Hu et al. (2019) developed a model where companies are facing problem due to product returns. The article allows dynamic pricing and resold those products that are in good conditions. Shah and Naik (2018), permitting discounts under price and stock-sensitive demand function. Stamatopoulos and Tzamos (2019) studied a model for monopolistic firm that updates its pricing dynamically to maximize total profit. Pervin et al. (2018) developed an inventory model for variable holding cost under trade-credit policy. Taleizadeh et al. (2012) introduced a muti-product stochastic inventory model for dynamic demand. Tan and Karabati (2013) structured a stock-out dependent dynamic demand model.

\section{Notations and Assumptions}

The notations as shown in Table 1 and assumptions used in model optimization problem are given below:

\subsection{Assumptions}

The inventory system is for single product.

(a) $p(t)=\left\{\begin{array}{l}p \quad, 0 \leq t \leq t_{d} \\ p \exp \left(-\delta\left(t-t_{d}\right)\right), t_{d} \leq t \leq T\end{array}\right.$

Here, $p$ is the initial selling price and $\delta>0$ is the discount variable, where $t_{d}$ represents the length of cycle time when there is no deterioration.

(b) The demand rate is a function of selling price and cumulative demand. 
International Journal of Mathematical, Engineering and Management Sciences

Vol. 6, No. 2, 510-521, 2021

https://doi.org/10.33889/IJMEMS.2021.6.2.031

$$
\dot{R}(t)=\left\{\begin{array}{l}
\dot{R}_{1}(t)=\alpha-\beta p-\lambda R_{1}(t), 0 \leq t \leq t_{d} \\
\dot{R}_{2}(t)=\alpha-\beta p \exp \left(-\delta\left(t-t_{d}\right)\right)-\lambda R_{1}(t), t_{d} \leq t \leq T
\end{array}\right.
$$

where, $\alpha$ represents market potential, $\beta$ is price sensitivity function, $\lambda$ is reducing rate of sales. It represents saturation effect. The parameter includes the ratio of marketplace that will not purchase the units at time $t$ because of market's saturation effects.

(c) The units in inventory deteriorate at constant rate and no replacement of perishable units is allowable during cycle time.

(d) During time period $\left[0, t_{d}\right]$, the deterioration rate is zero and after that the objects are getting deteriorate with constant rate $\theta$.

(e) Shortages are not permissible.

(f) The planning horizon is infinite.

(g) Replenishment rate is infinite with zero lead time.

(h) The retailer sells only single type of deteriorating objects during cycle time.

Table 1. Notations.

\begin{tabular}{|l|l|}
\hline $\mathrm{C}$ & Purchasing cost per unit (in \$/unit) \\
\hline$C_{d}$ & Disposing cost per unit (in \$/unit) \\
\hline$p(t)$ & Time dependent selling price per unit (in \$/unit) \\
\hline$t_{d}$ & The length of time when there is no deterioration. (in years) \\
\hline$h$ & Holding cost per unit per unit time during interval $\left[0, t_{d}\right]$ (in \$/unit) \\
\hline$h+\mu\left(t-t_{d}\right)$ & Holding cost per unit per unit time during $\left[t_{d}, T\right]$ (in \$/unit), where $\mu>0$ is rate of increase in holding cost \\
\hline$A$ & Ordering cost per order(in $\$ /$ order) \\
\hline$\alpha$ & Market potential $; \alpha>0$ \\
\hline$\beta$ & Price sensitivity factor $; \beta>0$ \\
\hline$\lambda$ & Decreasing rate of sales ; $\lambda>0$ \\
\hline$R(t)$ & Dynamic demand rate at $\mathrm{t}$ time \\
\hline$R_{1}(t)$ & Demand rate for the time $\left[0, t_{d}\right]$ \\
\hline$R_{2}(t)$ & Demand rate for the time $\left[t_{d}, T\right]$ \\
\hline$\theta$ & Constant deterioration rate, $0 \leq \theta<1$ \\
\hline$I_{1}(t)$ & Inventory during time $\left[0, t_{d}\right]$ \\
\hline$I_{2}(t)$ & Inventory during time $\left[t_{d}, T\right]$ \\
\hline$T$ & Cycle time (in years) \\
\hline$Q$ & The total order quantity \\
\hline$T P(T, p)$ & Total profit per unit time of inventory model (in $\$ /$ year) \\
\hline
\end{tabular}


International Journal of Mathematical, Engineering and Management Sciences

Vol. 6, No. 2, 510-521, 2021

https://doi.org/10.33889/IJMEMS.2021.6.2.031

\section{Mathematical Model}

In this section, a dynamic demand for deteriorating objects with time-dependent selling pricing is presented. The study focuses on monopolistic market. Figure1 represent the model.

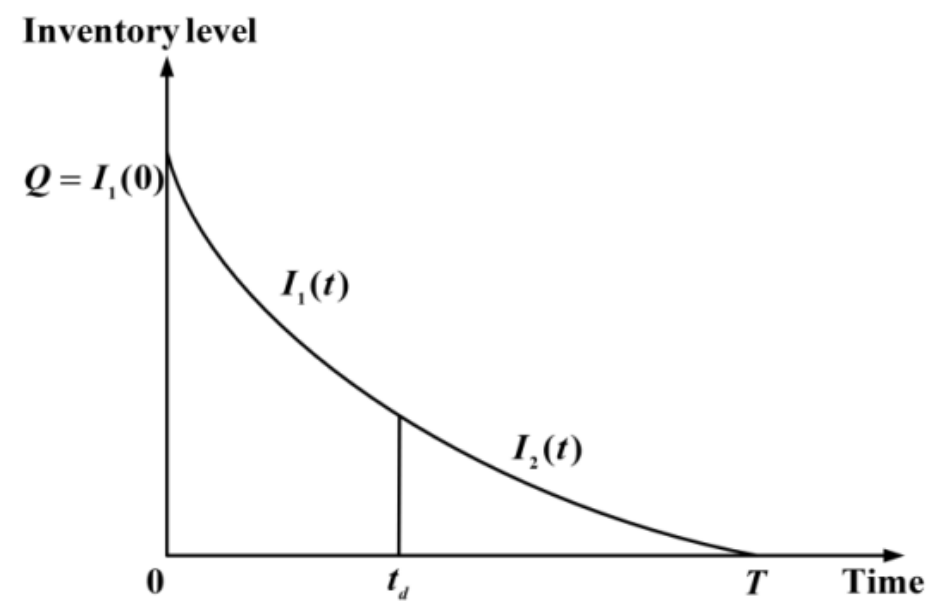

Figure 1. Inventory system.

In the beginning of each cycle, $Q$ units of product arrive at the firm. During time $\left[0, t_{d}\right]$, the inventory system reveals no deterioration and the quantity goes on decreasing due to demand only. In this case, the selling price of the product is given by $p(t)=p$ and the differential equation of dynamic demand rate for the time interval $\left[0, t_{d}\right]$ is

$\dot{R}_{1}(t)=\alpha-\beta p-\lambda R_{1}(t), 0 \leq t \leq t_{d}$

with boundary condition $R_{1}(0)=R_{0}$. The solution of equation (1) i.e. the $R_{1}(t)$ is given by

$R_{1}(t)=\frac{\alpha}{\lambda}(1-\exp (-\lambda t))+R_{0} \exp (-\lambda t)+\frac{\beta p}{\lambda}(\exp (-\lambda t)-1)$

The differential equation governing inventory level for time $\left[0, t_{d}\right]$ is

$\frac{d I_{1}(t)}{d t}=-R_{1}(t)=-\left(\frac{\alpha}{\lambda}(1-\exp (-\lambda t))+R_{0} \exp (-\lambda t)+\frac{\beta p}{\lambda}(\exp (-\lambda t)-1)\right)$

With boundary condition $I_{1}(0)=Q$, solving equation (3) yields,

$$
I_{1}(t)=\frac{-\alpha}{\lambda}\left(t+\frac{\exp (-\lambda t)}{\lambda}\right)+\frac{R_{0} \exp (-\lambda t)}{\lambda}+\frac{\beta p}{\lambda}\left(\frac{\exp (-\lambda t)}{\lambda}+t\right)+Q+\frac{\alpha}{\lambda^{2}}-\frac{R_{0}}{\lambda}-\frac{\beta p}{\lambda^{2}}
$$

During time $\left[t_{d}, T\right]$ the items start getting deteriorates with constant rate and the selling price in this case is given by $p(t)=p \exp \left(-\delta\left(t-t_{d}\right)\right)$. The dynamic demand rate is given by, 
International Journal of Mathematical, Engineering and Management Sciences

Vol. 6, No. 2, 510-521, 2021

https://doi.org/10.33889/IJMEMS.2021.6.2.031

$$
\dot{R}_{2}(t)=\alpha-\beta p \exp \left(-\delta\left(t-t_{d}\right)\right)-\lambda R_{2}(t)
$$

With boundary conditions, $R_{1}\left(t_{d}\right)=R_{2}(0)$. Solving, equation (5) the dynamic demand rate i.e. $R_{2}(t)$ is,

$$
\begin{aligned}
R_{2}(t) & =\frac{\alpha}{\lambda}-\frac{\beta p \exp \left(\delta\left(t_{d}-t\right)\right)}{\lambda-\delta}+\frac{\alpha}{\lambda}\left(\exp (-\lambda t)-\exp \left(-\lambda\left(t+t_{d}\right)\right)\right)+R_{0} \exp \left(-\lambda\left(t+t_{d}\right)\right) \\
& +\frac{\beta p}{\lambda}\left(\exp \left(-\lambda\left(t+t_{d}\right)\right)-\exp (-\lambda t)\right)-\frac{\alpha}{\lambda} \exp (-\lambda t)+\frac{\beta p}{\lambda-\delta} \exp \left(-\lambda t+\delta t_{d}\right)
\end{aligned}
$$

In this case the objects are start getting deteriorate. The inventory level decreases due to effect of both demand and deterioration. The differential equation of the inventory level during time interval $\left[t_{d}, T\right]$ is,

$$
\frac{d I_{2}(t)}{d t}=-R_{2}(t)-\theta I_{2}=-\left(\begin{array}{l}
\frac{\alpha}{\lambda}-\frac{\beta p \exp \left(\delta\left(t_{d}-t\right)\right)}{\lambda-\delta}+\frac{\alpha}{\lambda}\left(\exp (-\lambda t)-\exp \left(-\lambda\left(t+t_{d}\right)\right)\right) \\
+R_{0} \exp \left(-\lambda\left(t+t_{d}\right)\right)+\frac{\beta p}{\lambda}\left(\exp \left(-\lambda\left(t+t_{d}\right)\right)-\exp (-\lambda t)\right) \\
-\frac{\alpha}{\lambda} \exp (-\lambda t)+\frac{\beta p}{\lambda-\delta} \exp \left(-\lambda t+\delta t_{d}\right)
\end{array}\right)-\theta I_{2}
$$

having boundary condition $I_{2}(T)=0$. The solution of equation (7) is,

$$
\begin{aligned}
& I_{2}(t)=\frac{\alpha}{\theta \lambda}(\exp ((T-t) \theta)-1)+\frac{\alpha}{\lambda(\theta-\lambda)}\left(\exp \left(m_{2}\right)-\exp \left(m_{1}\right)\right)+\frac{R_{0}}{(\theta-\lambda)}\left(\exp \left(m_{1}\right)-\exp \left(m_{2}\right)\right) \\
& +\frac{\beta p}{(\lambda-\delta)(\theta-\delta)}\left(\exp \left(m_{5}\right)-\exp \left(m_{3}\right)\right)-\frac{\beta p}{\lambda(\theta-\lambda)}\left(\exp \left(m_{2}\right)-\exp (-\lambda t)-\exp \left(m_{1}\right)+\exp \left(m_{4}\right)\right) \\
& -\frac{\beta p \exp \left(\delta t_{d}\right)}{(\lambda-\delta)(\theta-\lambda)}\left(\exp (-\lambda t)-\exp \left(m_{4}\right)\right)
\end{aligned}
$$

where, $m_{1}=-\lambda t_{d}-T \lambda+T \theta-t \theta, m_{2}=-\lambda t_{d}-\lambda t, m_{3}=\delta t_{d}-T \delta+T \theta-t \theta$,

$m_{4}=-T \lambda+T \theta-t \theta$ and $m_{5}=\delta t_{d}-\delta t$.

The initial inventory level $Q$ is given by,

$$
Q=R_{1}\left(t_{d}\right) t_{d}+\int_{t_{d}}^{T} I_{2}\left(t_{d}\right) d t
$$

By substituting (9) into (4), equation (4) gives: 


$$
\begin{aligned}
I_{1}(t) & =\frac{-\alpha}{\lambda}\left(t+\frac{\exp (-\lambda t)}{\lambda}\right)+\frac{R_{0} \exp (-\lambda t)}{\lambda}+\frac{\beta p}{\lambda}\left(\frac{\exp (-\lambda t)}{\lambda}+t\right)+R_{1}\left(t_{d}\right) t_{d}+\int_{t_{d}}^{T} I_{2}\left(t_{d}\right) d t \\
& +\frac{\alpha}{\lambda^{2}}-\frac{R_{0}}{\lambda}-\frac{\beta p}{\lambda^{2}}
\end{aligned}
$$

The terms included in total profit of the system are explained as follows:

(I) Sales revenue $(\mathrm{SR})=\int_{0}^{t_{d}} p R_{1}(t) d t+\int_{t_{d}}^{T} p \exp \left(-\delta\left(t-t_{d}\right)\right) R_{2}(t) d t$,

(II) Ordering cost $(\mathrm{OC})=A$,

(III) Holding cost (HC) $=\int_{0}^{t_{d}} h I_{1}(t) d t+\int_{t_{d}}^{T}\left(h+\mu\left(t-t_{d}\right)\right) I_{2}(t) d t$,

(IV) Purchasing cost (PC) $=C Q=C\left(R_{1}\left(t_{d}\right) t_{d}+\int_{t_{d}}^{T} I_{2}\left(t_{d}\right) d t\right)$,

(V) Disposing cost (DC) $=C_{d} \int_{t_{d}}^{T} \theta I_{2}(t) d t$.

Hence, the total profit function per unit time is given by,

Total cost $(\mathrm{TP})=\frac{1}{\mathrm{~T}}(\mathrm{SR}-\mathrm{OC}-\mathrm{HC}-\mathrm{PC}-\mathrm{DC})$

The total cost per unit time is continuous function of cycle time $(T)$ and initial selling price $(p)$.

\section{Computational Algorithm}

To solve the problem, classical optimization method is used. The objective is to maximize the total profit function. The solution steps are as follows:

Step 1: Assign numerical values to all inventory parameters.

Step 2: Calculate first-order partial derivative for total profit function with respect to $T$ and $p$ as follows:

$$
\frac{\partial T P}{\partial p}=0, \frac{\partial T P}{\partial T}=0
$$

Step 3: To examine the concavity of total profit function, minor determinant is evaluated. A Hessian matrix is used and is given by,

$$
H=\left[\begin{array}{ll}
\frac{\partial^{2} T P}{\partial T^{2}} & \frac{\partial^{2} T P}{\partial T \partial p} \\
\frac{\partial^{2} T P}{\partial p \partial T} & \frac{\partial^{2} T P}{\partial p^{2}}
\end{array}\right] \text {, with minor determinant as } D_{1}=\frac{\partial^{2} T P}{\partial T^{2}}, D_{2}=\left|\begin{array}{ll}
\frac{\partial^{2} T P}{\partial T^{2}} & \frac{\partial^{2} T P}{\partial T \partial p} \\
\frac{\partial^{2} T P}{\partial p \partial T} & \frac{\partial^{2} T P}{\partial p^{2}}
\end{array}\right|
$$


International Journal of Mathematical, Engineering and Management Sciences

Vol. 6, No. 2, 510-521, 2021

https://doi.org/10.33889/IJMEMS.2021.6.2.031

For concavity, Hessian matrix $\mathrm{H}$ must be negative definite i.e. $D_{1}<0, D_{2}>0$.

Step 4: The obtained value of decision variables $(T, p)$ are being used in equation (11) to calculate the optimal profit function.

\section{Numerical Example and Sensitivity Analysis}

Example 1: Take $\alpha=30, \beta=0.1, C=\$ 50 /$ unit, $C_{d}=\$ 55 /$ unit, $h=\$ 2 /$ unit/year, $A=\$ 25 /$ order,$\theta$ $=0.2, \delta=0.005, \mu=0.4, \lambda=0.35, R_{0}=5, t_{d}=0.04$ year. Using the above solution procedure, the optimum value of decision variables are $T=0.759$ year, $p=\$ 230.09 /$ unit, $\mathrm{TP}=\$ 1263.84$.

To represent concavity, $D_{1}, D_{2}$ are calculated according to step 3 . The obtained values are $D_{1}=-662.76<0, D_{2}=42.528>0$.

The above result ensures the concavity of profit function. Also, the graph shown in Figure 2 represents the concavity of the optimality function.

A sensitivity analysis is performed in Table 2, representing a change in decision variables together with total profit function by changing inventory parameters up to $-20 \%,-10 \%, 10 \%$ and $20 \%$.

Results depending on the above sensitivity table are as follows:

(i) Parameter $\alpha$ can be interpreted as maximum demand that can be analysed by the companies at the initial stage of cycle time if the object is given for free i.e. market potential. With an increase in market potential there is an increase in initial selling price along with total cycle time. The increase is beneficial to the model as it helps the increase the total profit of retailer.

(ii) $\quad \beta$ is the objects own price effects. It indicates that sale of the product decreases when its selling price increases. The increment shows negative impact as it decreases the optimization problem. i.e. total profit function.

(iii) When purchase cost $(C)$ and disposing cost $\left(C_{d}\right)$ increases, the selling price of the products increases. It is obvious that an increase in selling price will directly influence the demand rate. Due to decrease in demand the total profit decreases. Hence, the increase is not preferable.

(iv) By increasing ordering cost and holding cost, the total profit decreases. As with an increase in deterioration rate, the retailers have to invest more to reduce damages.

(v) Higher deterioration rate increases the selling price. The change is not advisable as it decreases the total profit.

(vi) The increase in $t_{d}$ is good as it increases the total profit function. Depending on the products quality, if the deterioration free time increases the selling price decreases that helps to reduce the economic loss. One should prefer the products whose rate of deterioration is low. 
International Journal of Mathematical, Engineering and Management Sciences

Vol. 6, No. 2, 510-521, 2021

https://doi.org/10.33889/IJMEMS.2021.6.2.031

Table 2. Sensitivity analysis.

\begin{tabular}{|c|c|c|c|c|}
\hline Parameters & Values of parameters & Initial selling price $(p)$ (\$/unit) & $\begin{array}{c}\text { Cycle time } \\
(T) \text { (in years) }\end{array}$ & $\begin{array}{c}\text { Total profit } \\
(T P)(\text { in \$/year) }\end{array}$ \\
\hline \multirow{3}{*}{$\alpha$} & 30 & 230.09 & 0.760 & 1263.85 \\
\hline & 33 & 241.17 & 0.922 & 1492.03 \\
\hline & 36 & 255.26 & 1.052 & 1755.33 \\
\hline \multirow{4}{*}{$\beta$} & 0.09 & 249.31 & 0.868 & 1446.36 \\
\hline & 0.1 & 230.09 & 0.760 & 1263.85 \\
\hline & 0.11 & 214.99 & 0.664 & 1120.14 \\
\hline & 0.12 & 203.22 & 0.580 & 1004.33 \\
\hline \multirow{5}{*}{$C$} & 40 & 220.38 & 0.969 & 1331.25 \\
\hline & 45 & 224.97 & 0.859 & 1294.28 \\
\hline & 50 & 230.09 & 0.760 & 1263.85 \\
\hline & 55 & 236.07 & 0.667 & 1238.79 \\
\hline & 60 & 243.71 & 0.576 & 1218.35 \\
\hline \multirow{5}{*}{$C_{d}$} & 44 & 228.73 & 0.783 & 1270.05 \\
\hline & 49.5 & 229.41 & 0.772 & 1266.91 \\
\hline & 55 & 230.09 & 0.760 & 1263.85 \\
\hline & 60.5 & 230.78 & 0.748 & 1260.88 \\
\hline & 66 & 231.49 & 0.737 & 1257.98 \\
\hline \multirow{5}{*}{$h$} & 1.6 & 229.82 & 0.764 & 1265.04 \\
\hline & 1.8 & 229.95 & 0.762 & 1264.45 \\
\hline & 2.0 & 230.09 & 0.760 & 1263.85 \\
\hline & 2.2 & 230.22 & 0.757 & 1263.27 \\
\hline & 2.4 & 230.36 & 0.755 & 1262.67 \\
\hline \multirow{5}{*}{$\theta$} & 0.16 & 227.31 & 0.814 & 1275.13 \\
\hline & 0.18 & 228.68 & 0.786 & 1269.31 \\
\hline & 0.20 & 230.09 & 0.760 & 1263.85 \\
\hline & 0.22 & 231.53 & 0.734 & 1258.75 \\
\hline & 0.24 & 233.02 & 0.709 & 1253.94 \\
\hline \multirow{5}{*}{$A$} & 20 & 230.71 & 0.743 & 1270.50 \\
\hline & 22.5 & 230.38 & 0.752 & 1267.16 \\
\hline & 25 & 230.09 & 0.760 & 1263.85 \\
\hline & 27.5 & 229.81 & 0.767 & 1260.57 \\
\hline & 30 & 229.56 & 0.774 & 1257.34 \\
\hline \multirow{5}{*}{$t_{d}$} & 0.032 & 232.09 & 0.744 & 1254.77 \\
\hline & 0.034 & 231.06 & 0.752 & 1259.31 \\
\hline & 0.04 & 230.09 & 0.760 & 1263.85 \\
\hline & 0.044 & 229.18 & 0.766 & 1268.40 \\
\hline & 0.048 & 228.32 & 0.773 & 1272.94 \\
\hline \multirow{5}{*}{$\delta$} & 0.004 & 229.99 & 0.760 & 1264.13 \\
\hline & 0.0045 & 230.04 & 0.7599 & 1263.99 \\
\hline & 0.005 & 230.09 & 0.7595 & 1263.85 \\
\hline & 0.0055 & 230.13 & 0.7591 & 1263.71 \\
\hline & 0.006 & 230.18 & 0.758 & 1263.57 \\
\hline \multirow{5}{*}{$\mu$} & 0.32 & 230.07 & 0.7598 & 1263.90 \\
\hline & 0.36 & 230.08 & 0.7597 & 1263.88 \\
\hline & 0.4 & 230.087 & 0.7595 & 1263.85 \\
\hline & 0.44 & 230.09 & 0.7593 & 1263.83 \\
\hline & 0.48 & 230.10 & 0.7591 & 1263.80 \\
\hline \multirow{5}{*}{$\lambda$} & 0.28 & 229.07 & 0.809 & 1296.17 \\
\hline & 0.315 & 229.52 & 0.784 & 1279.69 \\
\hline & 0.35 & 230.09 & 0.760 & 1263.85 \\
\hline & 0.385 & 230.80 & 0.734 & 1248.64 \\
\hline & 0.42 & 231.67 & 0.708 & 1234.04 \\
\hline \multirow{4}{*}{$R_{0}$} & 4 & 216.78 & 0.905 & 1115.18 \\
\hline & 4.5 & 222.46 & 0.842 & 1186.73 \\
\hline & 5 & 230.09 & 0.760 & 1263.85 \\
\hline & 5.5 & 245.55 & 0.605 & 1349.64 \\
\hline
\end{tabular}


International Journal of Mathematical, Engineering and Management Sciences

Vol. 6, No. 2, 510-521, 2021

https://doi.org/10.33889/IJMEMS.2021.6.2.031

(vii) $\lambda$ represents the saturation effect. It represents the ratio of the market who will not buy the products as they already have it. The change shows negative impact because it reduces the sale that influences the total profit function. The total profit function decreases with an increase in saturation effect.

(viii) Increase in discount rate $\delta$ increases the sale but decreases the total profit function.

(ix) With an increase in $\mu$, the holding cost after time $t_{d}$ increases because of deterioration. Hence, the total profit function decreases.

(x) The total profit increases significantly by increasing $R_{0}$.

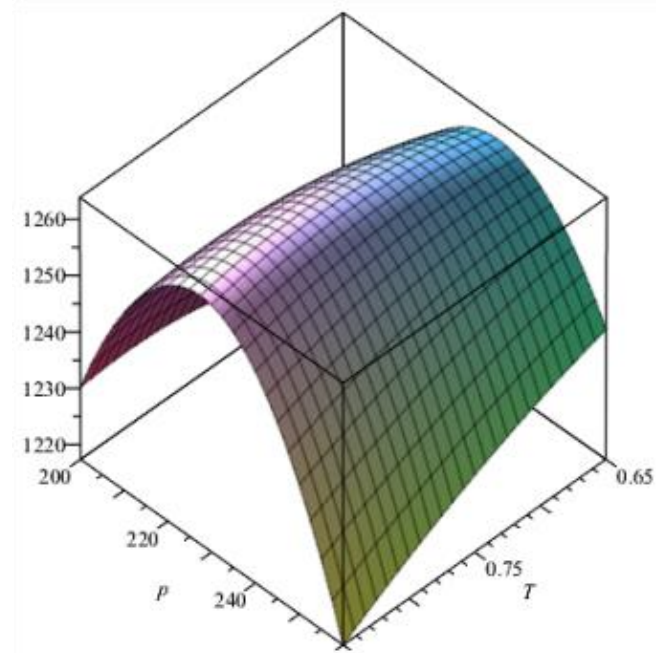

Figure 2. Concavity of total profit function through graphs.

\section{Conclusion}

This work is useful where the demand plays an important role in increasing the sale. The model helps to solve problems when the company is facing problems due to spoilage. During that time instead of constant selling price they can have variations with suitable discount for perishable products. Dynamic pricing is an effective tool in inventory models. This will help them to fulfil consumer's requirement according to their need. Specifically, when the consumer's demand is price sensitive, a firm can change the price accordingly with time. The model considers dynamic demand for perishable products in which the selling price is time sensitive and is an exponential function of discount rate when deterioration takes place. To reduce the complexity the rate of deterioration is assumed to be constant. The model uses classical optimization method to calculate the initial selling price and cycle time. The purpose of the model is to maximize the total profit function with respect to the decision variables. Concavity of the optimization problem is presented through graphs. Furthermore, sensitivity analysis is performed related to the inventory parameters along with some managerial insights. It shows that with an increase in deterioration rate the holding cost increases to prevent the spoilage which in turn decreases the total profit function. Also, the discount given during time period $\left[0, t_{d}\right]$ is not advisable as it increases the loss. Moreover, it is observed through sensitivity table that with an increase in deterioration free cycle time the total profit increases. Also, it is suggested that the company must sold as many 
International Journal of Mathematical, Engineering and Management Sciences

Vol. 6, No. 2, 510-521, 2021

https://doi.org/10.33889/IJMEMS.2021.6.2.031

products as possible before deterioration take place. For further research one can consider shortages, preservation technology investment, backordering and trade-credits. It may be extended further by taking multi-products at a time with more than one retailer or manufacturer.

\section{Conflict of Interest}

The authors do not have any conflict of interest.

\section{Acknowledgment}

Second author (kavita rabari) is funded by a Junior Research Fellowship from the Council of Scientific \& Industrial Research having (file no.-09/070(0067)/2019-EMR-I) and all the authors are thankful to DST-FIST file \# MSI-097 for their technical support to the Department of Mathematics, Gujarat University. Ekta Patel would like to extend sincere thanks to the Education Department, Gujarat State for providing scholarship under ScHeme of Developing High quality research.

\section{References}

Avinadav, T., Chernonog, T., Lahav, Y., \& Spiegel, U. (2017). Dynamic pricing and promotion expenditures in an EOQ model of perishable products. Annals of Operations Research, 248(1-2), 7591.

Bakker, M., Riezebos, J., \& Teunter, R.H. (2012). Review of inventory systems with deterioration since 2001. European Journal of Operational Research, 221(2), 275-284.

Bitran, G., \& Caldentey, R. (2003). An overview of pricing models for revenue management. Manufacturing \& Service Operations Management, 5(3), 203-229.

Cai, X., Feng, Y., Li, Y., \& Shi, D. (2013). Optimal pricing policy for a deteriorating product by dynamic tracking control. International Journal of Production Research, 51(8), 2491-2504.

Dasu, S., \& Tong, C. (2010). Dynamic pricing when consumers are strategic: Analysis of posted and contingent pricing schemes. European Journal of Operational Research, 204(3), 662-671.

Feng, L., Zhang, J., \& Tang, W. (2013). Optimal control of production and remanufacturing for a recovery system with perishable items. International Journal of Production Research, 51(13), 3977-3994.

Feng, L., Zhang, J., \& Tang, W. (2018). Dynamic joint pricing and production policy for perishable products. International Transactions in Operational Research, 25(6), 2031-2051.

Feng, Q., Luo, S., \& Shanthikumar, J.G. (2020). Integrating dynamic pricing with inventory decisions under lost sales. Management Science, 66(5), 2232-2247.

Golrezaei, N., Nazerzadeh, H., \& Randhawa, R. (2020). Dynamic pricing for heterogeneous time-sensitive customers. Manufacturing \& Service Operations Management, 22(3), 562-581.

Gupta, D., Hill, A.V., \& Bouzdine-Chameeva, T. (2006). A pricing model for clearing end-of-season retail inventory. European Journal of Operational Research, 170(2), 518-540.

Hsieh, T.P., \& Dye, C.Y. (2017). Optimal dynamic pricing for deteriorating items with reference price effects when inventories stimulate demand. European Journal of Operational Research, 262(1), 136150.

Hu, X., Wan, Z., \& Murthy, N.N. (2019). Dynamic pricing of limited inventories with product returns. Manufacturing \& Service Operations Management, 21(3), 501-518.

Pang, Z. (2011). Optimal dynamic pricing and inventory control with stock deterioration and partial backordering. Operations Research Letters, 39(5), 375-379. 
International Journal of Mathematical, Engineering and Management Sciences

Vol. 6, No. 2, 510-521, 2021

https://doi.org/10.33889/IJMEMS.2021.6.2.031

Pervin, M., Roy, S.K., \& Weber, G.W. (2018). An integrated inventory model with variable holding cost under two levels of trade-credit policy. Numerical Algebra, Control \& Optimization, 8(2), 169-191.

Qin, Y., Wang, J., \& Wei, C. (2014). Joint pricing and inventory control for fresh produce and foods with quality and physical quantity deteriorating simultaneously. International Journal of Production Economics, 152, 42-48.

Rabbani, M., Zia, N.P., \& Rafiei, H. (2015). Coordinated replenishment and marketing policies for noninstantaneous stock deterioration problem. Computers \& Industrial Engineering, 88, 49-62.

Shah, N.H., \& Naik, M.K. (2018). Inventory Policies for Price-Sensitive Stock-Dependent Demand and Quantity Discounts. International Journal of Mathematical, Engineering and Management Sciences, 3(3), 245-257.

Shah, N.H., \& Vaghela, C.R. (2017). Economic order quantity for deteriorating items under inflation with time and advertisement dependent demand. Opsearch, 54(1), 168-180.

Shah, N.H., Soni, H.N., \& Patel, K.A. (2013). Optimizing inventory and marketing policy for noninstantaneous deteriorating items with generalized type deterioration and holding cost rates. Omega, 41(2), 421-430.

Stamatopoulos, I., \& Tzamos, C. (2019). Design and dynamic pricing of vertically differentiated inventories. Management Science, 65(9), 4222-4241.

Taleizadeh, A.A., Niaki, S.T.A., \& Seyedjavadi, S.M.H. (2012). Multi-product multi-chance-constraint stochastic inventory control problem with dynamic demand and partial back-ordering: A harmony search algorithm. Journal of Manufacturing Systems, 31(2), 204-213.

Tan, B., \& Karabati, S. (2013). Retail inventory management with stock-out based dynamic demand substitution. International Journal of Production Economics, 145(1), 78-87.

Transchel, S., \& Minner, S. (2009). The impact of dynamic pricing on the economic order decision. European Journal of Operational Research, 198(3), 773-789.

Wee, H.M., \& Law, S.T. (2001). Replenishment and pricing policy for deteriorating items taking into account the time-value of money. International Journal of Production Economics, 71(1-3), 213-220.

Xue, M., \& Zhu, G. (2019). Partial myopia vs. forward-looking behaviors in a dynamic pricing and replenishment model for perishable items. Journal of Industrial \& Management Optimization, 13(5), $1-16$.

Xue, M., Tang, W., \& Zhang, J. (2016). Optimal dynamic pricing for deteriorating items with referenceprice effects. International Journal of Systems Science, 47(9), 2022-2031. 